\title{
Revision of tumor prosthesis of the knee joint
}

\author{
Yukihiro Yoshida $\cdot$ Shunzo Osaka · Toshio Kojima • \\ Masafumi Taniguchi $\cdot$ Eiji Osaka $\cdot$ Yasuaki Tokuhashi
}

Received: 12 May 2011 / Accepted: 30 July 2011 / Published online: 19 August 2011

(C) The Author(s) 2011. This article is published with open access at Springerlink.com

\begin{abstract}
Background Among 40 patients with primary malignant tumors of the knee joint who underwent reconstruction of the affected limb with tumor prosthesis, revision was required in 7 due to stem breakage or loosening.

Subjects and methods In the 7 cases undergoing revision, conditions and background factors at the time of breakage, the breakage site, time of revision, models of previous and new prostheses, stem diameters before and after revision, details of the revision (blood loss, operative time), and the presence or absence of adjuvant therapy were determined.

Results The replacement site was the distal femur in 5 and proximal tibia in 2. Revision was performed 6 years and 2 months after the previous prosthesis placement on average. The broken prosthesis model was KMFTR in 4 and
\end{abstract}

\footnotetext{
Y. Yoshida $(\bowtie) \cdot$ T. Kojima $\cdot$ M. Taniguchi $\cdot$ Y. Tokuhashi

Department of Orthopedic Surgery,

Nihon University School of Medicine,

30-1, Oyaguchikami-cho, Itabashi-ku, Tokyo 173-8610, Japan

e-mail: yyoshida@med.nihon-u.ac.jp;

yoshida.yukihiro@nihon-u.ac.jp

T. Kojima

e-mail: kojimat@med.nihon-u.ac.jp

M. Taniguchi

e-mail: mss_taniguchi@yahoo.co.jp

Y. Tokuhashi

e-mail: ytoku@med.nihon-u.ac.jp

S. Osaka $\cdot$ E. Osaka

Nerima Hikarigaoka Hospital, Nihon University,

2-11-1, Hikarigaoka, Nerima-ku, Tokyo, Japan

e-mail: sosaka@med.nihon-u.ac.jp

E. Osaka

e-mail: eosaka@med.nihon-u.ac.jp
}

HMRS and the physio-hinge type in one each. Revision due to loosening was performed in a case requiring replacement with Growing Kotz prosthesis. The model was switched to HMRS in 3, and the stem diameter was changed to $12 \mathrm{~mm}$ in 3 KMFTR breakage cases. The mean stem diameters were 11.2 and $10.2 \mathrm{~mm}$ in the non-revision and revision groups. The respective resection rates were 36 and $45 \%$. The mean functional evaluation was $70.1 \%$ before and $76.2 \%$ after revision.

Conclusion To reduce the risk of tumor prosthesis breakage, the amount of bone resection should be limited to $30 \%$ or less in the affected bone, the stem diameter should be at least $12 \mathrm{~mm}$, and the stem shape should be fitted to the anatomical shape of the femur.

Keywords Limb salvage - Revision - Tumor prostheses . Malignant bone tumor

\section{Background}

Various methods, such as allografting [1, 2], pasteurized autografting [3], and bone elongation [4], have recently been employed for the reconstruction of limbs affected by malignant bone tumors. However, reconstruction with tumor prosthesis remains the primary treatment. Tumor prosthesis use is advantageous in that it facilitates stable function of the affected limb and an early return to social activities. The survival rate of patients treated with tumor prosthesis was satisfactory in a recent report [5]. However, there are potentially serious complications, including infection, breakage, and loosening. We recently experienced a case in which tumor prosthesis of the knee joint (Howmedica Modular Reconstruction System (HRMS) broke 13 years after surgery. Reportedly, tumor prostheses breakage is caused 
by increased patient activity and loosening of the stem. When wide resection is performed for a malignant bone tumor around the knee joint, the surrounding soft tissue is also resected. Thus, a hinge-type prosthesis is inevitably needed to stabilize the knee joint. Breakage of the stem is thus reportedly due to the design of the prosthesis [5]. The causes of breakage are thought to include the stem diameter, the length of resected bone, and prosthesis design. Forty patients with primary malignant tumors around the knee joint underwent limb salvage by reconstruction with prosthesis use. To investigate the causes underlying breakage of prostheses, we divided these patients into those with (7) and without (33) revision of a broken or loose stem. The prosthesis model, stem diameter, length of resected bone, and International Symposium on Limb Salvage (ISOLS) $\mathrm{X}$-ray evaluation were determined in each case. In the 7 revision cases, elements assumed to be causative were analyzed in detail to identify problems and possible countermeasures.

\section{Materials and methods}

The 40 subjects had primary malignant tumors of the knee joint and underwent limb salvage by reconstruction with a prosthesis in our department between 1979 and 2008.

The subjects comprised 20 women and 20 men, ranging in age from 7 to 82 years (mean age, 27.5 years). The pathological diagnosis of the primary lesion was osteosarcoma in 28 , chondrosarcoma in 5 , bone malignant fibrous histiocytoma (MFH) in 3, and a giant cell tumor GCT (grade 3), synovial sarcoma, Ewing's sarcoma, and a primitive neuroectodermal tumor (PNET)in one each. The duration of follow-up ranged from 1 year and 5 months to 19 years (mean: 11 years and 2 months). The 7 patients who underwent replacement were 6 women and 1 man, ranging in age from 7 to 44 years (mean age, 26.5 years). The primary lesion was osteosarcoma in 4, and PNET, GCT (grade 3), and synovial sarcoma in one each. The duration of followup after the initial examination ranged from 12 to 19 years (mean: 16 years). The prosthesis model, replacement site, stem diameter, length of resected bone, resection rate, and ISOLS X-ray evaluation were investigated in all 40 cases. In the 7 cases undergoing revision, conditions and background factors at the time of breakage, breakage site, time of revision, models of previous and new prostheses, stem diameters before and after revision, details of the revision (blood loss, operative time, surgical procedure), and the presence or absence of adjuvant therapy were also investigated. In addition, ISOLS X-ray and functional evaluations were performed before revision and at the final follow-up.

\section{Results}

Replacement site and time of revision

The prosthesis replacement site was the distal femur in 28 and the proximal tibia in 12 cases. Among the 7 cases requiring revision due to stem breakage or loosening, the replacement site was the distal femur in 5 and the proximal tibia in 2. The shortest and longest times until revision for breakage and loosening, after the initial wide resection followed by reconstruction of the tumor affected limb or an elongation-type prosthesis placement, were 10 months and 11 years, respectively, with a mean of 6 years and 2 months.

Prosthesis models used in the initial replacement and the revision

At the initial replacement in our 40 cases, the Howmedica Modular Reconstruction System (HMRS) was used in 22, and the rotating hinge type in two. The Kotz Modular Femur and Tibia Reconstruction System (KMFTR) was used in 6, the Growing Kotz in 10, the Kyocera custommade prosthesis in one, and the Kyocera PH1 (physio-hinge type 1) in one. The broken models in the 7 revision cases were the KMFTR in 4, and HMRS and physio-hinge type I in one each. Revision for loosening of the stem was performed in a 7-year-old female with PNET who had undergone reconstruction of the distal femur with a Growing Kotz (Case 2). The model used for revision was the HMRS in 3 cases reconstructed with a KMFTR at the initial replacement excluding a proximal tibial case (Case 2). In Case 38, a PH type 1 with an 11-mm stem diameter was changed to the slightly thicker PH type 2 with a $12-\mathrm{mm}$ stem diameter. In Case 39, the stem diameter $(12 \mathrm{~mm})$ of the new prosthesis was the same as that before breakage. However, the new stem, at $15 \mathrm{~cm}$, was longer. In Case 2, a new component was prepared, considering that the tibial component of the HMRS employed for adults is too large. The new tibial component was designed with proximal and distal diameters of 15 and $10 \mathrm{~mm}$, respectively, and a stem length of $14 \mathrm{~cm}$, and the stem was entirely covered with a porous coating (Tables 1,2).

\section{Stem diameter}

The stem diameters ranged from 8 to $14 \mathrm{~mm}$ (mean: $11.1 \mathrm{~mm}$ ) in our 40 cases. In the non-revision cases, they ranged from 8 to $14 \mathrm{~mm}$ (mean: $11.2 \mathrm{~mm}$ ). In the revision cases, the diameters ranged from 9 to $12 \mathrm{~mm}$ (mean: $10.2 \mathrm{~mm}$ ), the diameter of the broken KMFTR was $10 \mathrm{~mm}$ in all 4 cases. The prosthesis was changed to one with a stem diameter of $12 \mathrm{~mm}$ in 3 of these 4 cases. In Case 39, 
Table 1 List of cases with reconstruction of regions around the knee joint using prostheses

\begin{tabular}{|c|c|c|c|c|c|c|c|c|}
\hline Case & Age & Gender & $\begin{array}{l}\text { Pathological } \\
\text { diagnosis }\end{array}$ & Model & $\begin{array}{l}\text { Replacement } \\
\text { site }\end{array}$ & $\begin{array}{l}\text { Resected } \\
\text { length }(\mathrm{cm})\end{array}$ & $\begin{array}{l}\text { Stem diameter } \\
(\mathrm{mm})\end{array}$ & $\begin{array}{l}\text { Resection } \\
\text { rat }(\%)\end{array}$ \\
\hline 1 & 7 & M & OS & Growing Kotz & DF & 14 & 8 & 36.80 \\
\hline 2 & 7 & $\mathrm{~F}$ & PNET & Growing Kotz & DF & 21 & 9 & 53 \\
\hline 3 & 11 & M & OS & Growing Kotz & DF & 13 & 11 & 33 \\
\hline 4 & 16 & $\mathrm{~F}$ & OS & Growing Kotz & DF & 13 & 10 & 31 \\
\hline 5 & 10 & $\mathrm{~F}$ & OS & Growing Kotz & DF & 15 & 9 & 45 \\
\hline 6 & 12 & M & OS & Growing Kotz & DF & 17 & 10 & 44 \\
\hline 7 & 8 & M & OS & Growing Kotz & PT & 12 & 10 & 50 \\
\hline 8 & 12 & M & Ewing sarcoma & Growing Kotz & PT & 15 & 10 & 35 \\
\hline 9 & 16 & $\mathrm{~F}$ & OS & Growing Kotz & PT & 10 & 10 & 33 \\
\hline 10 & 12 & $\mathrm{~F}$ & OS & Growing Kotz & PT & 16 & 10 & 32 \\
\hline 11 & 34 & M & OS & HMRS & PT & 16 & 12 & 47 \\
\hline 12 & 60 & $\mathrm{~F}$ & OS & HMRS & DF & 16 & 14 & 38 \\
\hline 13 & 57 & $\mathrm{~F}$ & Chondrosarcoma & HMRS & $\mathrm{DF}$ & 12 & 11 & 35 \\
\hline 14 & 18 & $\mathrm{~F}$ & OS & HMRS & PT & 12 & 12 & 34 \\
\hline 15 & 57 & $\mathrm{~F}$ & Chondrosarcoma & HMRS (Rotating) & $\mathrm{DF}$ & 12 & 12 & 26 \\
\hline 16 & 27 & $\mathrm{~F}$ & OS & HMRS & $\mathrm{DF}$ & 18 & 13 & 39 \\
\hline 17 & 25 & M & OS & HMRS & DF & 17 & 13 & 34 \\
\hline 18 & 24 & M & OS & HMRS & PT & 13 & 11 & 37 \\
\hline 19 & 12 & $\mathrm{~F}$ & OS & HMRS & DF & 18.5 & 12 & 42 \\
\hline 20 & 20 & M & MFH of bone & HMRS & PT & 14.5 & 11 & 47 \\
\hline 21 & 25 & M & OS & HMRS (Rotating) & DF & 12 & 12 & 27 \\
\hline 22 & 27 & M & OS & HMRS & DF & 16 & 12 & 33 \\
\hline 23 & 56 & $\mathrm{~F}$ & Chondrosarcoma & HMRS & PT & 18 & 12 & 47 \\
\hline 24 & 16 & M & OS & HMRS & DF & 12 & 10 & 30 \\
\hline 25 & 13 & M & OS & HMRS & DF & 16 & 12 & 27 \\
\hline 26 & 18 & M & OS & HMRS & DF & 14 & 12 & 43 \\
\hline 27 & 20 & M & OS & HMRS & DF & 12 & 13 & 29 \\
\hline 28 & 66 & $\mathrm{~F}$ & MFH of bone & KMFTR & DF & 12 & 11 & 27 \\
\hline 29 & 82 & M & Chondrosarcoma & KMFTR & DF & 16 & 12 & 34 \\
\hline 30 & 27 & M & OS & HMRS & PT & 17 & 11 & 45 \\
\hline 31 & 52 & $\mathrm{~F}$ & OS & Kyocera (cement) & DF & 16 & 11 & 35 \\
\hline 32 & 50 & M & Chondrosarcoma & HMRS & DF & 18 & 11 & 48 \\
\hline 33 & 41 & M & GCT & HMRS & PT & 13 & 12 & 40 \\
\hline 34 & 44 & $\mathrm{~F}$ & OS & KMFTR & DF & 12 & 10 & 23 \\
\hline 35 & 31 & $\mathrm{~F}$ & OS & KMFTR & PT & 12 & 10 & 34 \\
\hline 36 & 26 & $\mathrm{~F}$ & OS & KMFTR & $\mathrm{DF}$ & 23 & 10 & 54 \\
\hline 37 & 40 & $\mathrm{~F}$ & Synovial sarcoma & KMFTR & DF & 14 & 10 & 48 \\
\hline 38 & 15 & M & OS & PH type1 (cement) & DF & 18 & 11 & 55 \\
\hline 39 & 28 & $\mathrm{~F}$ & OS & HMRS & DF & 22 & 12 & 48 \\
\hline 40 & 66 & $\mathrm{~F}$ & MFH of bone & HMRS & DF & 18 & 12 & 38 \\
\hline
\end{tabular}

$D F$ distal femur, $P T$ proximal femur, HMRS Howmedica Modular Resection System, KMFTR Kotz Modular Femoral and Tibia Replacement, PH type 1 physio-hinge type 1, PH type 2 physio-hinge type 2

the stem diameter $(12 \mathrm{~mm})$ of the new prosthesis was the same as that of the broken one, but the new stem was longer $(15 \mathrm{~cm})$. In Case 2, the stem region of the tibial component of the Growing Kotz employed in the initial replacement had proximal and distal stem diameters of 12 and $9 \mathrm{~mm}$, respectively, and a length of $10 \mathrm{~cm}$. On revision, it was replaced with a new porous-coated tibial component with proximal and distal diameters of 15 and $10 \mathrm{~mm}$, respectively, and a length of $14 \mathrm{~cm}$. Screw breakage was noted in Cases 37 and 39. 
Table 2 Revision cases managed by our department

\begin{tabular}{|c|c|c|c|c|c|c|c|c|c|}
\hline Case & Age & Sex & Location & $\begin{array}{l}\text { Time of revision } \\
(\mathrm{mon})(\mathrm{m})\end{array}$ & Type & $\begin{array}{l}\text { Diameter } \\
(\mathrm{mm})\end{array}$ & $\begin{array}{l}\text { Screw } \\
\text { breakage }\end{array}$ & $\begin{array}{l}\text { Type of new } \\
\text { prosthesis }\end{array}$ & Diameter \\
\hline Case 34 & 44 & $\mathrm{~F}$ & Distal femur & 48 & KMFTR & 10 & - & HMRS & $12 \mathrm{~mm}$ \\
\hline Case 35 & 31 & $\mathrm{~F}$ & Proximal tibia & 84 & KMFTR & 10 & - & KMFTR & $10 \mathrm{~mm}$ \\
\hline Case 36 & 26 & $\mathrm{~F}$ & Distal femur & 10 & KMFTR & 10 & - & HMRS & $12 \mathrm{~mm}$ \\
\hline Case 37 & 40 & $\mathrm{~F}$ & Distal femur & 28 & KMFTR & 10 & + & HMRS & $12 \mathrm{~mm}$ \\
\hline Case 38 & 15 & M & Distal femur & 108 & PH type1 & 11 & - & PH type 2 & $12 \mathrm{~mm}$ \\
\hline Case 39 & 28 & $\mathrm{~F}$ & Distal femur & 132 & HMRS & 12 & + & HMRS & $12 \mathrm{~mm}$ \\
\hline Case 2 & 7 & $\mathrm{~F}$ & Proximal tibia & 113 & Growing Kotz & $\begin{array}{l}\text { Proximal: } 12 \\
\text { Distal: } 9\end{array}$ & - & Growing Kotz & $\begin{array}{l}\text { Proximal: } 15 \mathrm{~m} \\
\text { Distal: } 10 \mathrm{~mm}\end{array}$ \\
\hline
\end{tabular}

Resected bone length

The respective maximum and minimum lengths of resected bone including the tumor region were 12 and $23 \mathrm{~cm}$, with a mean of $15.4 \mathrm{~cm}$. Those in the 33 non-revision cases were 10 and $18.5 \mathrm{~cm}$, respectively, with a mean of $14.6 \mathrm{~cm}$. In the 7 revision cases, these lengths were 12 and $22 \mathrm{~cm}$, respectively, with a mean of $17.7 \mathrm{~cm}$ (Table 1).

\section{Resection rate of affected bone}

The resected region accounted for $27-50 \%$ (mean: 36 ) in the 33 non-revision cases, and 23-53\% (mean: $45 \%$ ) in the 7 revision cases. Thus, the ratio of the resected region was greater, comprising nearly half of the affected bone, in cases undergoing revision for breakage or loosening (Table 1).

Conditions and backgrounds of patients at the time of breakage

The stem was broken in 6 patients. Five had experienced sudden pain in the femoral or knee joint regions, while walking. They visited our hospital, and breakage was identified on X-ray examination. In the other patient (Case 39), dull pain appeared in the proximal femoral region and had become severe about 4 months later. At this time, breakage was identified. Only this patient was actively engaged in activities such as dancing and mountain climbing, while the other 6 were not especially involved in athletic activities. Regarding the social backgrounds of these 7 patients, Cases 34-37 were housewives, Case 38 was a clerical employee, mainly working at a desk, Case 39 was a speech therapist, and Case 2 was a student.

ISOLS X-ray and functional evaluations

X-ray evaluation was performed at the final follow-up in all 40 cases, and all items pertaining to bone remodeling, interface, and anchorage were graded as excellent in about $70 \%$ of these patients. However, in the revision group, the interface before revision was graded as poor and fair in Cases 2 and 39, respectively, and anchorage was graded as fair in all cases. After revision, bone remodeling was graded as poor only in Case 38, in whom the bone cortex around the stem was thinned by more than $1 / 3$. A radiolucent line was also noted in the interface, resulting in a grading of fair. Functional evaluation was performed before revision and at the final postrevision follow-up. The evaluation was 5380\% (mean: $70.1 \%$ ) before and $63-86 \%$ (mean: $76.2 \%$ ) after revision (Table 3 ).
Table 3 Functional and radiological assessments and the presence/absence of adjuvant therapy before and after replacement

\begin{tabular}{|c|c|c|c|c|c|}
\hline \multirow{9}{*}{$\begin{array}{l}\text { Table } 3 \text { Functional and radio- } \\
\text { logical assessments and the } \\
\text { presence/absence of adjuvant } \\
\text { therapy before and after } \\
\text { replacement }\end{array}$} & \multicolumn{3}{|c|}{ Functional assessment } & \multicolumn{2}{|c|}{ Radiographical assessment } \\
\hline & Case & Before & After & Before replacement & After replacement \\
\hline & & repracement (\%) & repracement (\%) & $\begin{array}{l}\text { Bone remodeling/ } \\
\text { interface/ } \\
\text { anchorage }\end{array}$ & $\begin{array}{l}\text { Bone remodeling/ } \\
\text { interface/ } \\
\text { anchorage }\end{array}$ \\
\hline & Case 34 & 78 & 80 & $\mathrm{E} / \mathrm{G} / \mathrm{F}$ & $\mathrm{G} / \mathrm{G} / \mathrm{E}$ \\
\hline & Case 35 & 75 & 78 & $\mathrm{E} / \mathrm{G} / \mathrm{F}$ & $\mathrm{G} / \mathrm{G} / \mathrm{E}$ \\
\hline & Case 36 & 76 & 73 & $\mathrm{E} / \mathrm{E} / \mathrm{F}$ & $\mathrm{F} / \mathrm{E} / \mathrm{E}$ \\
\hline & Case 37 & 73 & 74 & $\mathrm{G} / \mathrm{G} / \mathrm{F}$ & $\mathrm{G} / \mathrm{G} / \mathrm{E}$ \\
\hline & Case 38 & 80 & 63 & $\mathrm{G} / \mathrm{G} / \mathrm{F}$ & $\mathrm{P} / \mathrm{F} / \mathrm{G}$ \\
\hline & Case 39 & 60 & 80 & $\mathrm{G} / \mathrm{F} / \mathrm{F}$ & $\mathrm{G} / \mathrm{G} / \mathrm{E}$ \\
\hline $\begin{array}{l}E \text { excellent, } G \text { good, } F \text { failure, } \\
P \text { poor }\end{array}$ & Case 2 & 53 & 86 & $\mathrm{G} / \mathrm{P} / \mathrm{F}$ & $\mathrm{E} / \mathrm{E} / \mathrm{E}$ \\
\hline
\end{tabular}

$E$ excellent, $G$ good, $F$ failure, $P$ poor 
Table 4 Adjuvant therapy and details of revision surgery

\begin{tabular}{llll}
\hline Case & $\begin{array}{l}\text { Adjuvant } \\
\text { therapy }\end{array}$ & $\begin{array}{l}\text { Blood } \\
\text { loss }(\mathrm{g})\end{array}$ & $\begin{array}{l}\text { Operation } \\
\text { time (min) }\end{array}$ \\
\hline Case 34 & + & 430 & 200 \\
Case 35 & - & 370 & 260 \\
Case 36 & + & 282 & 212 \\
Case 37 & + & 330 & 240 \\
Case 38 & + & 155 & 210 \\
Case 39 & + & 600 & 220 \\
Case 2 & + & 420 & 371 \\
\hline
\end{tabular}

Details of revision (blood loss and operative time)

The shortest and longest operative times in the 7 cases were $3 \mathrm{~h}$ and $20 \mathrm{~min}$ and $6 \mathrm{~h}$ and $11 \mathrm{~min}$, respectively, with a mean of $4 \mathrm{~h}$ and $7 \mathrm{~min}$. The minimum and maximum blood losses were 155 and $600 \mathrm{~g}$ (mean: $369 \mathrm{~g}$ ), respectively (Table 4).

Presence or absence of adjuvant therapy

Case 33 in the revision group was diagnosed with a grade 3 GCT of the bone, and underwent surgery alone. Pre- and postoperative chemotherapies were administered in the other 6 cases. In Case 2, radiotherapy (50 Gy) was additionally performed for local control, after the completion of preoperative chemotherapy (Table 4).

\section{Discussion}

Recent advancements in surgical approaches and chemotherapy for primary malignant bone tumors have increased survival rates. The usefulness of reconstruction methods for affected limbs, including prostheses, has also been confirmed. However, complications associated with prostheses, such as infection, loosening, and breakage, remain problematic. Regarding stem breakage, in 1994, Capanna et al. [6] reported that stem breakage occurred in $6(6.3 \%)$ of 95 cases treated with modular uncemented tumor prostheses. In 2001, Mittenmayer et al. [5] reported that major complications occurred in 19 of 100 cases with uncemented tumor prostheses, 11 of these involved aseptic loosening, and septic loosening and implant fracture occurred in 4 each. In 2006, Gosheger reported that stem breakage occurred in 4 (1.6\%) of 250 cases with uncemented tumor prostheses [7]. In our department, breakage occurred after 5 years and 6 months on average, with the earliest being 10 months and latest 11 years. The models used were the KMFTR in 4 and the HMRS and PH type 1 in one case each. The stem diameters of $10 \mathrm{~mm}$ in 4 and $11 \mathrm{~mm}$ in one case were relatively thin for distal femoral stems. After revision, the stem diameter was $10 \mathrm{~mm}$ in only one, being thicker in all other cases. Although increased activity of patients and stem loosening were considered to be the causes of stem breakage, the design of the prostheses may have contributed to breakage, because the prostheses generally had a hinge-type structure [8]. In 2005, Griffin et al. reported that the incidence of KMFTR stem breakage involving the proximal tibia rose when the stem diameter was small, and the length of resected bone increased. They also described cases of distal femoral replacement: the 5-year survival rates were 35,85 , and $71.2 \%$ in patients in whom the distal femoral stem sizes were $10-12,13$, and $14-16 \mathrm{~mm}$, respectively. These observations showed that the stem diameter, rather than the resection length, was related to breakage in cases undergoing distal femoral replacement. We also focused on the stem diameter and the length of resected bone. We investigated the stem diameter and resection rate in all 40 cases. The mean stem size of $10.2 \mathrm{~mm}$ in the revision cases and $11.2 \mathrm{~mm}$ in the non-revision cases confirmed that a thin stem was used in the revision cases. Currently, 11-15-mm straight types and 12-15-mm curved types of diaphysisfixing pieces are available for HMRS.

All stems with a $10-\mathrm{mm}$ diameter are of the Growing Kotz and KMFTR types. In cases reconstructed with the HMRS, stems with a relatively small diameter, 11 or $12 \mathrm{~mm}$, were used in $80 \%$. This may reflect the Japanese physique. The mean resection rate was $34.7 \%$ in the nonrevision and $45 \%$ in the revision cases. The length of resected bone was thus greater in the revision than in the non-revision cases. When the resection rate is almost $45 \%$ in the clinical setting, possible reconstruction methods other than the use of a tumor prosthesis include total femoral replacement and biological reconstruction [3, 9, 10]. However, these reconstruction methods are indicated in only limited cases. When a tumor prosthesis is used, attention should be paid to the bone resection rate.

Comparison by region, such as the femoral and proximal tibial regions, was not possible because of the small number of cases. However, we would not expect more stress to be loaded on a thin stem used for a region from which a large amount of bone was excised. Griffin et al. also reported that stem breakage occurred in $6(6.1 \%)$ of 99 cases reconstructed with the KMFTR. These breakages occurred at 3 holes in the stem, indicating a structural problem. They stated that the ideal design of a prosthesis may be a strong and thick stem without holes to stop lateral movement, which facilitates bone ingrowth comparable or superior to that around the KMFTR stem. Aseptic loosening of the stem may be another cause of stem breakage. In our 40 patients, loosening was apparently present at the interface, being graded as poor in Cases 2 and 8 with a Growing Kotz. It was also graded as poor in Case 15, a 
57-year-old female with distal femoral chondrosarcoma in whom a rotating hinge-type HMRS was applied. The incidence of aseptic loosening varies among reports, ranging from as low as 1 and 5\% up to 26 and 29\% [11-18]. In 2001, Mittermayer et al. reported that aseptic loosening occurred in $27 \%$ of cases with complications involving stems [5]. In 1990, they developed an anatomically curved stem, which fit in the femoral bone marrow cavity to avoid stress shielding generated by firm fixation around the stem. Then in 1996, they rotated the hinge-type HMRS. The incidence of aseptic loosening in cases receiving this type of prosthesis was approximately $10 \%$ during a $42-134$-month follow-up period. Aseptic loosening is considered to be related to a patient's activity level. However, only in our Case 39 (28-year-old female) in the revision group had a high activity level, i.e., such a tendency was not apparent in our patients. Functional and X-ray evaluations following revision were favorable over the short, medium, and long term in various reports $[6,11,14,17]$. A similar tendency was noted in our patients. However, a 40-mm leg length discrepancy remained after surgery in our Growing Kotzrevised cases, resulting in a functionally unsatisfactory outcome.

We experienced 6 cases requiring revision for stem breakage. The shortest and longest operative times in the 7 revision cases were $3 \mathrm{~h}$ and $20 \mathrm{~min}$ and $6 \mathrm{~h}$ and $11 \mathrm{~min}$, respectively, with a mean of $4 \mathrm{~h}$ and $7 \mathrm{~min}$, and the minimum, maximum, and mean blood losses were 155,600 , and $369 \mathrm{~g}$, respectively. The levels of surgical stress may have been similar to that in the first wide resection with regard to the operative time and blood loss. Tang and Sim reported the revision procedures for stem breakage $[19,20]$. The goals of distal femoral revision are to cut-off the femoral bone cortex using a Surge Airtome or drill following the shape of the stem. This requires great care to avoid breakage of the cut-out bone cortex upon removal of the broken stem. A new stem must also be inserted, followed by returning the cut-off bone cortex block to its original position. Concerning reaming, we ream the femoral medullary cavity to a diameter $1 \mathrm{~mm}$ larger than that determined by preoperative measurement in principle. However, when the medullary cavity is narrow, reaming is performed to the stem diameter selected based on preoperative measurement. When a trial stem can be inserted, the real stem is inserted. When a trial stem cannot be inserted, over-reaming by $1 \mathrm{~mm}$ is performed. In revision surgery, since a thicker stem is inserted, over-reaming by $1 \mathrm{~mm}$ is always performed. Firm fixation is then with a cable. At this point, it is also necessary to add autologous or artificial bone grafting to assure sufficient future strength [21] (Figs. 1,2).

Based on the above observations, stem size, shape, and porous coating serve as countermeasures against stem breakage, as does bone grafting to the bone stump and

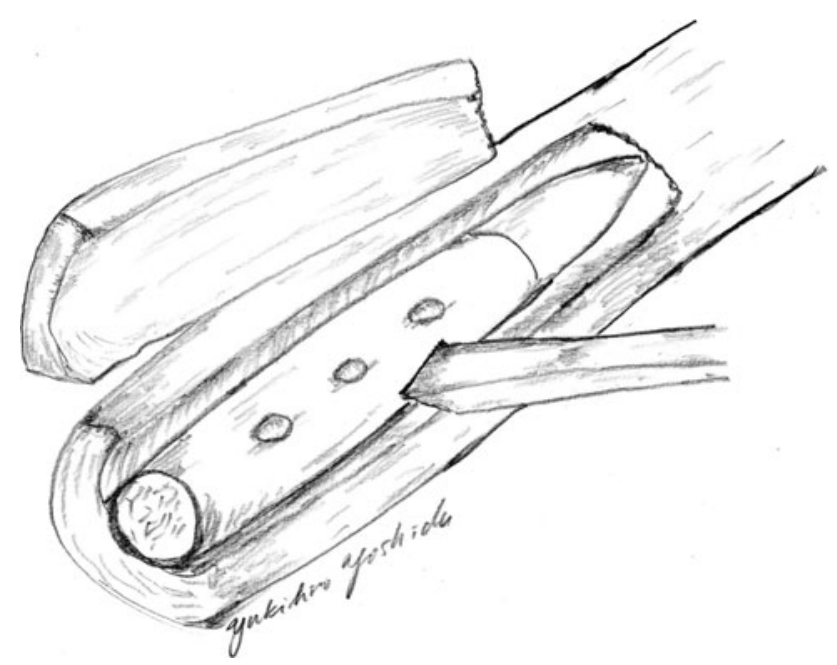

Fig. 1 The residual stem in the femur was carefully cut off using a Surge Airtome or chisel. It is important to carefully remove the broken stem because of intense bone ingrowth. Attention should also be paid to avoiding breakage of the fenestrated bone fragment and to return it to the original position after placement of the new stem

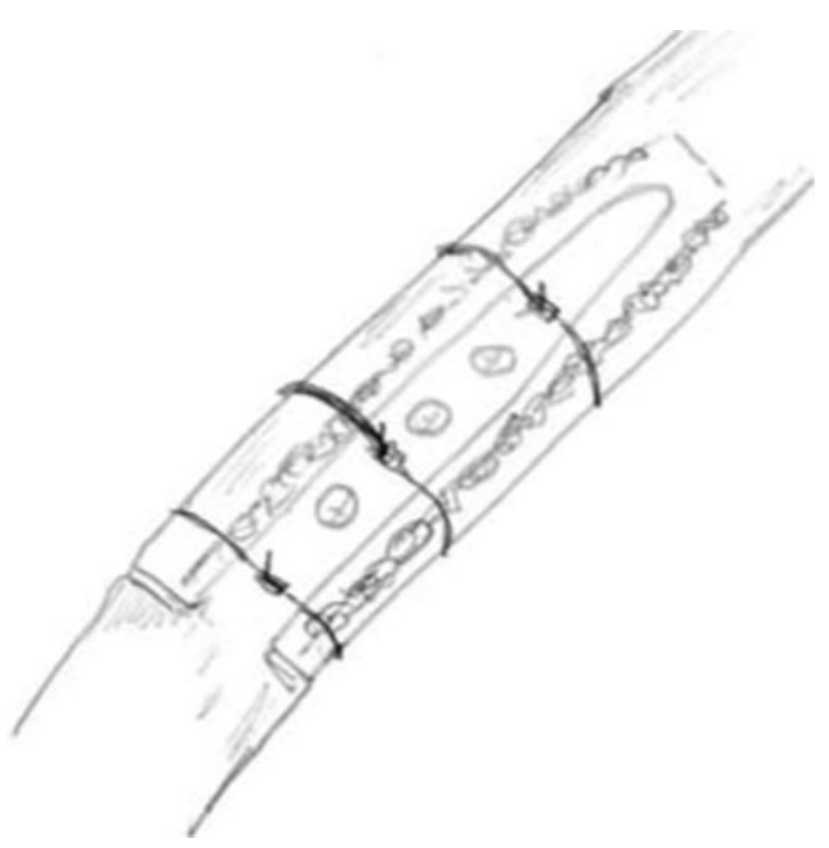

Fig. 2 After placement of the new stem, bone grafting is performed around the stem as shown. The use of a cable should also be considered for achieving stronger fixation

preservation of the periosteum $[5,11]$. However, no ideal prosthesis has as yet been established, though many researchers have investigated and developed various promising models [11]. Based on this study, we consider the following points to be important for avoiding prosthetic stem breakage: (1) Minimizing the length of bone resected, i.e., it is desirable not to exceed one third of the affected bone by employing a limited operation, and (2) selection of a stem diameter of at least $12 \mathrm{~mm}$. For the femur, the use of a 
curved stem should be investigated in consideration of the anatomical shape of this bone.

Regarding limb salvage for malignant bone tumors in children, an elongation-type prosthesis can be lengthened to correspond to the predicted leg length discrepancy, when employed for wide resection of a periarticular tumor including the joint [22-30]. A characteristic of the elongation-type Growing Kotz is the porous coating on the diaphysis-fixing piece of the elongation region. In contrast, non-porous processing is added to the non-elongation region. However, this structure may create susceptibility to loosening. When a pediatric patient grows more than expected, particularly, in the transverse axis of the proximal tibia, loosening and burying of the stem start and slowly progress. This ultimately, compresses the bone cortex. Although the Growing Kotz can be elongated with growth, the prosthetic design, particularly the width of the tibial component, should be sufficiently investigated in consideration of the child's development.

\section{Conclusion}

Prosthesis use facilitates the early acquisition of stable functioning of the affected limb, but several complications have yet to be overcome. Breakage and loosening necessitate revision in some cases. Methods considered to reduce the risk of prosthesis breakage, include limiting resection of the affected bone to no more than $30 \%$ and adoption of as thick a stem as possible, i.e., with a diameter of at least $12 \mathrm{~mm}$, fitting the anatomical shape of the femur. The unchanged function of the affected limb after revision and instructing of patients to avoid excessive exercise in daily activities are also important for maintenance of prostheses. Although only the elongation-type of Growing Kotz is covered by the national health insurance system in Japan, this prosthesis should also be selected with care, taking the child's future development into consideration.

Conflict of interest None of the authors has received any type of support, benefits, or funding from any commercial party related directly or indirectly to the subject of this article.

Open Access This article is distributed under the terms of the Creative Commons Attribution Noncommercial License which permits any noncommercial use, distribution, and reproduction in any medium, provided the original author(s) and source are credited.

\section{References}

1. Gebhardt MC, Flugstad DI, Springfield DS, Mankin HJ (1991) The use of bone allografts for limb salvage in high-grade extremity osteosarcoma. Clin Orthop Relat Res 270:181-196

2. Asada N, Tsuchiya H, Kitaoka K, Mori Y, Tomita K (1997) Massive autoclaved allografts and autografts for limb salvage surgery
A 1-8 year follow-up of 23 patients. Acta Orthop Scand 68:392395

3. Manabe J, Kawaguchi N, Matsumoto S (2001) Pasteurized autogenous bone graft for reconstruction after resection of malignant bone and soft tissue tumors: imaging features. Semin Musculoskeletal Radiol 5:195-200

4. Tsuchiya H, Abdel-Wanis ME, Tomita K (2006) Biological reconstruction after excision of juxta-articular osteosarcoma around the knee: a new classification system. Anticancer Res 26(1):44-53

5. Mittermayer F, Krepler P, Dominkus M, Schwameis E, Sluga M, Heinzl H, Kotz R (2007) Long-term followup of uncemented tumor endoprostheses for the lower extremity. Clin Orthop Relat Res 388:167-177

6. Capanna R, Morris HG, Capanacci D, Delben M, Capanacci M (1994) Modular uncemented Prosthetic reconstruction after resection of tumours of the distal femur. J Bone Joint Surg [Br] 76:178186

7. Gosheger G, Gebert C, Ahrens H, Stretbuerger A, Winkelmann W, Hards J (2006) Endoprosthetic reconstruction in 250 patients with sarcoma. Clin Orthop Relat Res 450:164-171

8. Griffin AM, Parsons JA, Davis AM, Bell RA, Wunder JS (2005) Uncemented tumor endoprostheses at the knee: root causes of failure. Clin Orthop Relat Res 438:71-79

9. Kalra S, Abudu A, Murata H, Grimer RJ, Tilman RM, Carter SR (2010) Total femur replacement primary procedure for treatment of malignant tumours of the femur. Eur J Surg Oncol 36(4):378383

10. Sabo D, Bernd L, Bunchner M, Treiber M, Wannenmacher M, Ewerbeck V, Parsch D (2003) Intraoperative extracorporeal irradiation and replantation in local treatment of primary malignant bone tumors. Orthopade 32(11):1003-1012

11. Choong PF, Sim FH, Pritchard DJ, Rock MG, Chao EY (1996) Megaprostheses after resection of distal femoral tumors. A rotating hinge design in 30 patients followed for 2-7 years. Acta Orthop Scand 67(4):345-351

12. Kawai A, Lin PP, Boland PJ, Athanasian EA, Healey JH (1999) Relationship between magnitude of resection, complication, and prosthetic survival after prosthetic knee reconstructions for distal femoral tumors. J Surg Oncol 70:109-115

13. Kawai A, Healey JH, Boland PJ, Athanasian EA, Jeon DG (1999) A rotating-hinge knee replacement for malignant tumors of the femur and tibia. J Arthroplasty 14:187-196

14. Kawai A, Muschler GF, Lane JM, Otis JC, Healey JH (1998) Prosthetic knee replacement after resection of a malignant tumor of the distal part of the femur. Medium to long-term results. J Bone Joint Surg Am 80:636-647

15. Zwart HJ, Taminiau AH, Schimmel JW, van Horn JR (1994) Kotz modular femur and tibia replacement. 28 tumor cases followed for 3 (1-8) years. Acta Orthop Scand 65:315-318

16. Witt JD, Marsden FW (1994) The functional evaluation of patients with primary malignant tumours about the knee treated by modular endoprosthetic replacement. Aust NZ J Surg 64:542-546

17. Unwin PS, Cannon SR, Grimer RJ, Kemp HB, Sneath RS, Walker PS (1996) Aseptic loosening in cemented custom-made prosthetic replacements for bone tumours of the lower limb. J Bone Joint Surg [Br] 78:5-13

18. Unwin PS, Cobb JP, Walker PS (1993) Distal femoral arthroplasty using custom-made prostheses. The first 218 cases. J Arthroplasty $8(3): 259-268$

19. Tang X, Guo W, Yang R, Yan T, Qu H (2010) Revision surgery for custom-made tumor prosthesis of knee joint. Zhongguo Xiu Fu Chong Jian Wai Ke Za Zhi 24(1):5-10

20. Sim IW, Tse LF, Ek ET, powell GJ, Choong PF (2007) Salvaging the limb salvage: management of complications following endoprosthetic reconstruction for tumours around the knee. Eur J Surg Oncol 33(6):796-802 
21. Yoshida Y, Osaka S, Tokuhashi Y (2009) Clinical experience of novel interconnected porous hydroxyapatite ceramics for the revision of tumor prosthesis: a case report. World J Surg Oncol 7:76

22. Mittermayer F, Windhager R, Dominkus M, Krepler P, schwameis E, Sluga M, Kotz R, Strasser G (2007) Revision of the Kotz type of tumour endprosthesis for the lower limb. J Bone Joint Surg [Br] 84:401-406

23. Myers GJ, Abudu AT, Carter SR, Tillman RM, Grimer RJ (2007) Endoprosthetic replacement of the distal femur for bone tumours. J Bone Joint Surg [Br] 89:521-526

24. Scales JT, Sneath RS (1987) The extending prosthesis. In: Coombs $\mathrm{R}$, Friedlander $\mathrm{G}$ (eds) Bone tumor management. Butterworth, London, pp 168-177

25. Lewis MM (1986) Use of expandable and adjustable prosthesis in the treatment of childhood malignant bone tumors of the extremity. Cancer 57:499-502
26. Kotz R, Schiller C, Windhager R, Ritschl P (1991) Endoprostheses in children: first results. In: Langlais F, Tomeno B (eds) Limb salvage: major reconstruction in oncologic and nontumoral conditions. Springer, Berlin, pp 591-599

27. Schindler OS, Cannon SR, Briggs TWR et al (1997) Stanmore custom-made extendabible distal femur replacements. Clinical experience in children with primary malignant bone tumors. J Bone Joint Surg [Br] 79:927-937

28. Schiller C, Windhager R, Fellinger EJ et al (1995) Extendable tumor endoprostheses for the leg in children. J Bone Joint Surg [Br] 77:608-614

29. Dominkus M, Krepler P, Schwameis E et al (2001) Growth prediction in extendable tumor prostheses in children. Clin Orthop Relat Res 390:212-220

30. Grimer RJ, Carter SR, Tillman RM, Sneath RS, Walker PS, Unwin PS, Shewell PC (1999) Endoprosthetic replacement of the proximal tibia. J Bone Joint Surg [Br] 81:488-494 